\title{
Object-Based on Land Cover Classification on LAPAN-A3 Satellite Imagery Using Tree Algorithm (Case Study: Rote Island)
}

\author{
Agus Herawan ${ }^{\text {a, }}$, Atriyon Julzarika ${ }^{\text {, }}$, Patria Rachman Hakim ${ }^{a}$, Ega Asti Anggari ${ }^{\text {a }}$ \\ ${ }^{a}$ Satellite Technology Center, Jl. Cagak satelit Km. 04, Rancabungur, Bogor, 16310, Indonesia \\ ${ }^{b}$ Remote Sensing application Center, Jl. l. Kalisari No. 8, Pekayon, Pasar Rebo, Jakarta, 13710, Indonesia \\ Corresponding author: *agus.herawan@lapan.go.id
}

\begin{abstract}
LAPAN became serious about making a remote sensing satellite on its third-generation satellite. Launched a year after LAPAN-A2, the third-generation satellite, LAPAN-A3, brought LISAT as the main payload. LISAT is a multispectral camera with 4 bands (Red, Green, Blue, NIR) that can be used for land classification, agriculture monitoring, drought monitoring, and land use changing. LAPAN-A3 is the third generation of micro-satellite developed by Satellite Technology Center - LAPAN. This satellite carries a multispectral push-broom sensor that can record the earth's surface at the visible and near-infrared spectrum. This paper aims to determine object-based land cover classification in Rote Island using the LAPAN-A3 satellite image using the tree method algorithm. This classification technique is expected to increase the accuracy of land cover classification. This classification used the LAPAN-A3 satellite imagery of Rote Island. The first process was determined the segmentation with scale parameter 60, shape 0.5 , and compactness 0.5. The result shows that OBIA classification on Rote Island, the area of the open land class is $233.67 \mathrm{~km}^{2}$, the area of the settlement is $11.57 \mathrm{~km}^{2}$, the body of water is $2006.21 \mathrm{~km} 2$, the area of low vegetation is $525.93 \mathrm{~km}^{2}$, the area of high vegetation is $437.5 \mathrm{~km}$, and there is no data (cloud and cloud shadows) on the LAPAN-A3 image of $45.78 \mathrm{~km}^{2}$. The accuracy values obtained were producer $86.67 \%$, KIA 83.02\%, Helden $92.86 \%$, Short $86.7 \%$, KIA per class $82.72 \%$, and $85.96 \%$. This object-based classification can meet international and national land cover classification standards, namely at $80 \%$.
\end{abstract}

Keywords - LAPAN-A3; obia; segmentation; tree algorithm; Rote.

\section{INTRODUCTION}

Spatial data ashore cover is broadly utilized for different financial and ecological applications, metropolitan and provincial arranging, preservation, and regular asset the board. One approach to get spatial data ashore cover is by utilizing far-off detecting pictures. Distant detecting picture covers a wide region inclusion and can incorporate high spatial and fleeting goals just as time and cost-effectiveness.

The land cover data can be acquired by removing Geobia actual boundaries, understanding, and picture grouping. LAPAN-A3/IPB is far off detecting satellite which has two obtaining multispectral imager mode. The recorded mode is a satellite recording of the image captured at the earth on memory before downloading to the ground station the next day. This mode captures the target area until $700 \mathrm{~km}$ length (7.5 km satellite velocity) [1].

As a polar sun-synchronous satellite, LAPAN-A3/IPB only passes Indonesia two to three times in the daytime. Therefore, real-time, more worthwhile cause produces twice as much as image coverage compared to recorded mode [2]. Both mode work is based on a schedule which uploads from Rancabungur ground station every night. When a satellite passing in the area target, the satellite automatically captures the image.

Based on processing, classification consists of two types, namely manual and digital. The manual classification includes digitizing on-screen, while the digital classification includes pixel-based classification and based classification objects. The method used for classification digital includes unsupervised, supervised, and decision tree

LAPAN-A3 imagery can improve land cover characterization. A geospatial way to deal with order landcover is required. Distant detecting innovation is one of the answers for landcover grouping, specifically ObjectBased Image Analysis (OBIA).

The technique utilized is a multispectral picture translation of the arrangement of controlled Object-Based Image Analysis (OBIA) with the division calculation [3]. The division is performed utilizing a calculation Multiresolution Segmentation and Spectral Difference Segmentation OBIA 
an item-based characterization to characterize object classes on parts of unearthly and spatial angles all the while [4]. This technique can defeat the shortcoming of arrangement strategies for this also is per-pixel, or pixels working at the individual level with the article framed through a cycle of division is the way toward gathering nearby pixels with a similar quality [5] OBIA endeavors to decipher the manual visual understanding basic methodology into a mechanized, computerized approach.

Phiri et al. [6] apply LANDSAT satellite imagery in Atmospheric and typographic errors that influence land cover classification. In this analysis, the atmospheric corrections for moderate resolution atmospheric transmission (MODTRAN) and dark object subtraction (DOS). According to the findings, the results showed non-pre-processed images had a classification accuracy of 68 percent for panned images and 66 percent for regular Landsat OLI-8 images. When combined MODTRAN and cosine topographic correction pre-processing was used, classification accuracy improved to 93 percent (pan-sharpened) and 86 percent (standard).

Sari and Fildes [7] explored the utilization of OBIA of SPOT-6 symbolism with the plan of building up a land cover guide of Nagan Raya by expected to deliver data at scale $1: 25,000$ that will improve arrangement exactness than those created utilizing regular visual and ghostly based techniques to help of the Indonesian public timberland checking framework.

Ela and Claire [8] used obia techniques and data fusion to perform a land-use calcification analysis. The findings revealed that the OBIA technique was very successful in classifying urban land cover. The accuracy obtained in this study ranged from 89 to 94 percent. Baker and Smith [9] investigated the use of GIS and OBIA approaches with Worldview-2 high-resolution imagery to classify the surface of a city park in Leicester, England.

Comert et al. [10] have mapped landslides using OBIA techniques from UAV data. Object-based classification using UAVs is more accurate and quicker than traditional mapping methods. The results showed that landslide mapping with OBIA had an accuracy of 86 percent Iro [11] examined object-based grouping to recognize its job in crevasse improvement in Nigeria.

Harto et al. [12] have utilizing grouping utilizing OBIA technique is superior to the customary arrangement, for example, a most extreme probability characterization strategy to distinguish banana plants. Hidayat [13] has talked about the execution of GEOBIA for waterfront planning in Indonesia. Some exploration consolidated pixel based and GEOBIA techniques, and some get the general precision $>70 \%$ of GEOBIA strategy. This exploration was helped by utilizing UAVs in Riau Province, to be exact, around the Liong River zone, Bengkalis.

Stephane et al. [14] conducted multisource satellite imagery research, and geospatial reference data were used to create land cover maps of Antananarivo (Madagascar's capital). A single VHSR Pleiades picture, a time series of Sentinel-2 and Landsat- 8 images, a Digital Terrain Model (DTM) are used. Robson et al. [15] has identified rock glaciers from satellite data by novel methods. Deep learning and object-based image analysis are combined in this research process.
Luciano et al. [16] have used OBIA to map sugarcane areas in the Sao Paolo state of Brazil. At ten sites around SP, binary random forest (RF) classification models were calibrated using multi-temporal data from Landsat images. Amatya et al. [17] have developed a system called Semi-Automatic Landslide Detection. OBIA techniques and machine learning by combining packages from pythons were used to map landslides in the Nepalese region. The accuracy obtained in this mapping is 70 percent.

From satellite imagery and spatial data, Machado and Quintanilha [18] established trip generators. In Joao Pessoa City, Brazil, the OBIA approach technique was used to identify LULC. Simanjuntak et al. [19] compared the local climate zone in Bandung based on high-resolution imagery, in this case, using Pleades and SPOT-6 imagery with Landsat satellite imagery.

The classification method used in comparing the local climate zone is the random forest method on Landsat and OBIA images on Pleades and SPOT-6 images. This study shows that the object-based OBIA technique provides an accuracy of 89 percent compared to a pixel-based random forest of 69 percent.

In Iran's Sahand Mountain, Feizizadeh [20] used OBIA to study volcanic and glacial landforms. Caldera, volcanic cone, tuff formation, andesite lava, dacite lava, glacier valley, suspension valley, and glacier cirque were discovered and categorized into eight categories. All class's overall accuracies were 96.2 percent, 93.3 percent, 92.4 percent, 94.2 percent, 93.01, 95.1, 90.1, and 90.5 percent, respectively.

Dornik et al [21] used two approaches to classify soil types: Geobia and Random Forest. The Geobia approach was found to be more efficient and superior in mapping soil types. The accuracy of object-based land maps is 58 percent. Land maps based on pixels are $10 \%$ more expensive.

This investigation intends to build up a spatial model of pilgrim thickness in Pontianak. The spatial model utilized is the NDBI record which is then joined with the OBIA-based arrangement. OBIA is a way to deal with the cycle the arrangement is not just viewed as the unearthly perspectives however the spatial parts of the item. The article framed through the division cycle, which is a cycle gathering of contiguous pixels with a similar quality (closeness otherworldly. OBIA with the details of the cycle, the investigation depends on ghastly and spatial appearance considered proficient in obliging the picture with the article's presence in the goal picture medium spatial.

The usage of OBIA is more reasonable for high-goal satellite symbolism. A large portion of the order procedures created utilizes ghastly factors as opposed to spatial data. The range-based arrangement approach is more open to applying than the spatial segment, particularly in utilizing high-goal pictures. This high-goal picture condition will, in general, have more range changeability and more welds as well. The advancement of other order techniques is expected to beat the issues in these high-goal pictures.

The spatial-relevant grouping is proposed to show the connection between the objective pixel and the neighboring pixels. The spatio-literary arrangement is gathered into surface extraction, Markov plane demonstrating, picture division, and article-based picture examination. This examination means to decide object-based land cover order 
strategies in LAPAN-A3 satellite pictures utilizing the tree calculation technique.

\section{MATERIALS AND METHOD}

Topographically, Rote Island is situated at $10^{\circ} 25^{\prime}-11^{\circ} 00^{\prime}$ South Latitude and $121^{\circ} 49^{\prime}-123^{\circ} 26^{\prime}$ East Longitude. The examination territory is situated in Rote Island, Rote Ndao District in 2018. Topographically, Rote Island is situated in the south of Indonesia, correctly in the area of East Nusa Tenggara. Extraordinarily this island has land qualities and biodiversity.

The information utilized in this investigation is LAPANA3 satellite symbolism with a spatial goal of $15 \mathrm{~m}$. LAPANA3 satellite symbolism has four groups: Red, Green, Blue, and Near Infra-Red (NIR). Repetition Island is an ideal territory to test land-use order utilizing the OBIA strategy.

This exploration uses LA3_20190620_023236_RB information from LAPAN-A3/IPB, which catch from an ongoing mode with a lossy pressure calculation. An Image has a 15 -meter goal, $120 \mathrm{~km}$ area width, and 21 days return to time [22]. Picture from continuous mode has a 12-bit radiometric goal, not quite the same as a recorded mode that has 16 radiometric goals. The picture caught in nadir pointing where imaging mission was directed along satellite ground track [22]. The image display of Rote Island, as shown in Fig 1.

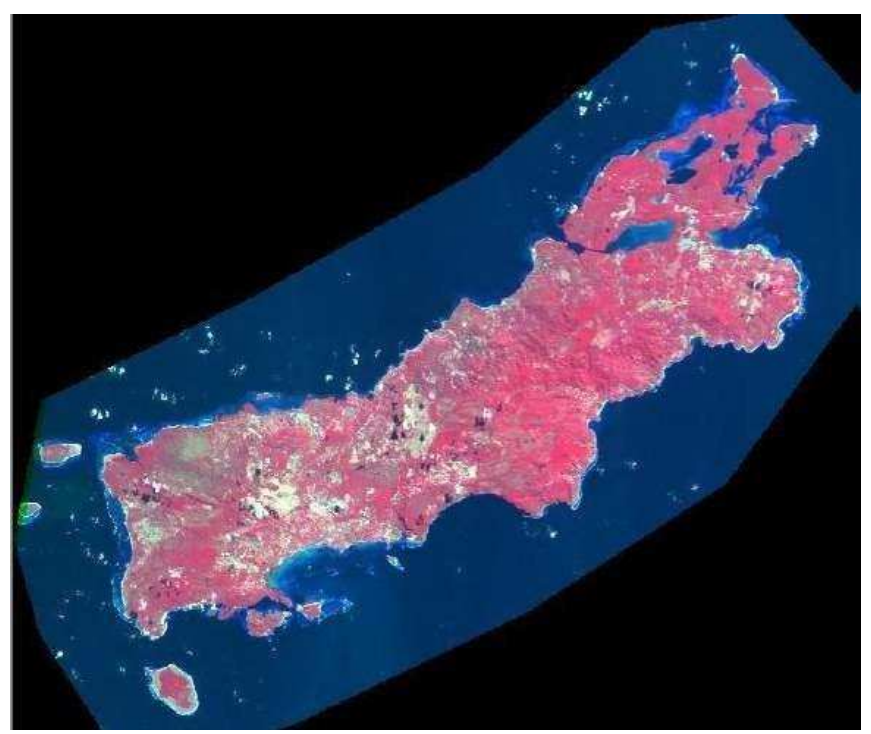

Fig. 1 Rote Island from LAPAN-A3 satellite

The method used in this study is shown in Fig 2.

\section{A. Pre-processing}

The image has been corrected, including radiometric correction and geometric correction. The radiometric correction has been done to minimize the vignetting and dark effect in the image before the satellite orbits. A vignetting effect caused by imperfect lens geometry causes the image's centre to look brighter than the corner parts.

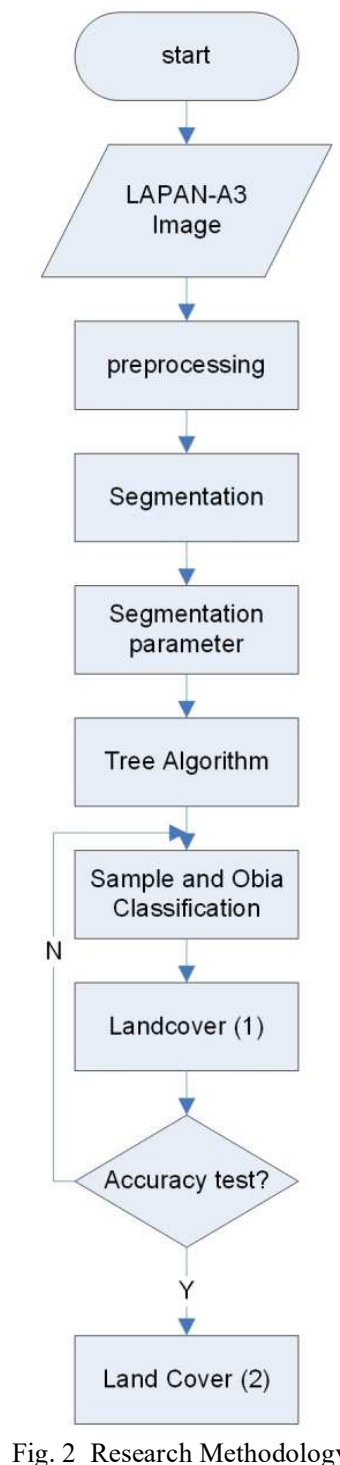

This effect might cause two identical objects in a different position in the image to have different digital number values. If this effect is not corrected, it can cause miss interpretation in the image postprocessing. The dark effect is small circle noises in the image caused by the different detector responsivity. Geometric correction using systematic correction software developed in Pusteksat LAPAN has been done. High geometry quality image produces during image acquisition, camera, and satellite in stable movement.

There are three requirements to produce an image with high geometry quality. The requirements are camera must in nadir pointing, attitude data must accurate, and camera orientation must be known.

LAPAN-A3/IPB uses open-loop mode to control attitude satellite. This mode only uses the pitch axis to control the satellite after the spin stabilization process, while the roll and yaw axis has a smooth movement. The open-loop mode generally does not cause significant image geometry problems. Sometimes, geometric correction using systematic correction software is not enough to reduce geometric distortion.

Therefore, a ground control point (GCP) is applied to correct unsystematic random geometric distortion. The image of LAPAN-A3/IPB registration with an image from Landsat 
8 is a reference image. We use affine (linear) transformation as spatial interpolation, with Root Mean Square Error (RMSE) $\leq 10$, hence no severe geometric error in the dataset.

\section{B. Segmentation}

This segmentation aims to separate object boundaries with high accuracy and better precision. This method of separation between objects uses a region growing. The object referred to in this study is a combination of several pixels with the same shape and compactness conditions at a specific scale. This OBIA classification uses parameters scale 60 , shape 0.5 , and compactness 0.5 . These three parameters are the main parameters in obtaining other parameters. Other parameters are density and asymmetry. The segmentation parameter is shown in Fig 3.

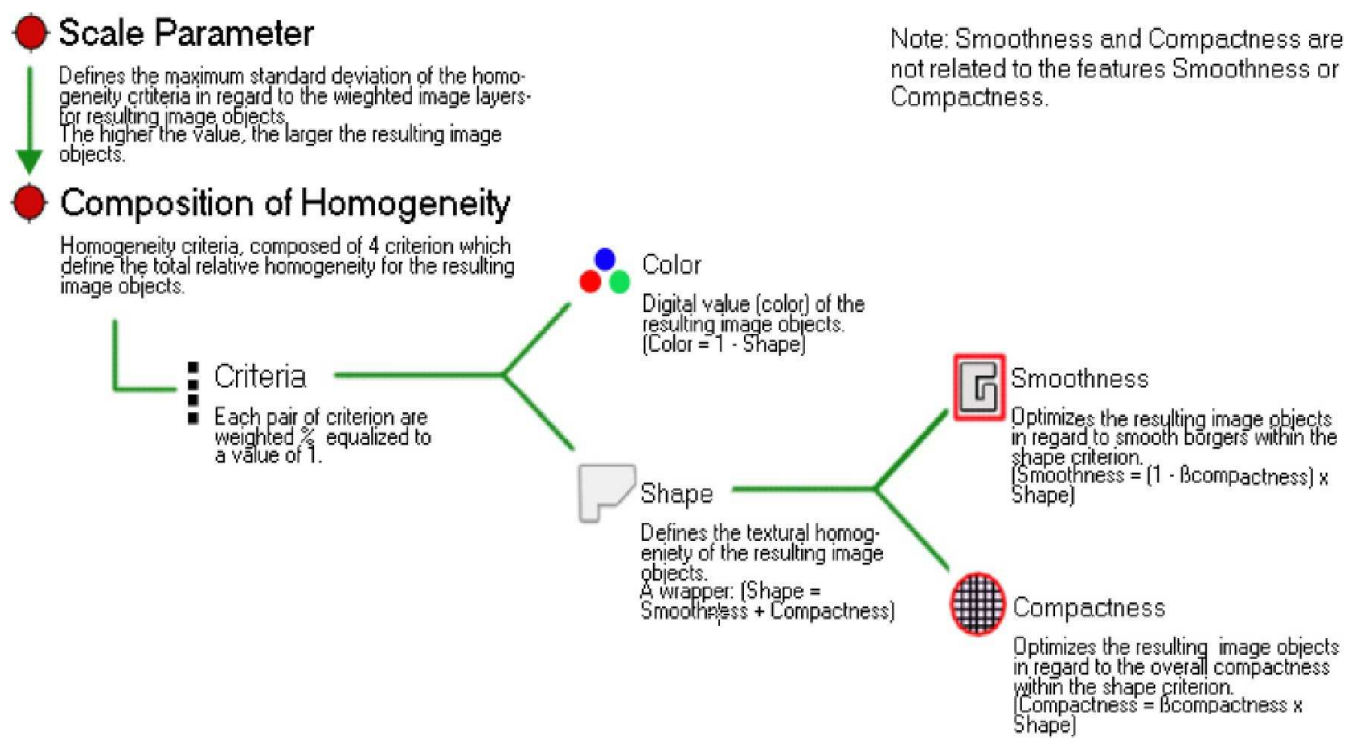

Fig. 3 Flow diagram of Multiresolution segmentation

\section{Tree Algorithm}

The land cover classification was conducted in this study object-based method tree algorithm. This object-based classification use segmentation parameters with a scale criterion of 30 , shape 0.5 , and compactness 0.5 . This segmentation aims to separate the object's boundary with higher accuracy and better precision, as in Fig. 4.

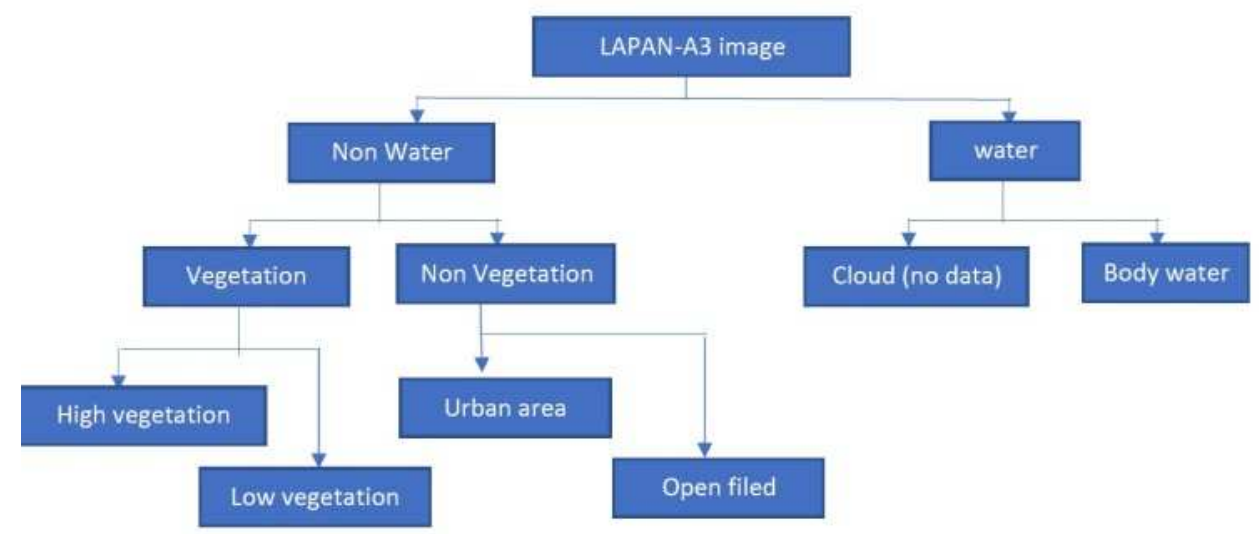

Fig. 4 Tree Algorithm

Method this separation between objects uses regions growing. That object referred to in this study is a combination of some pixels with shape and condition the same compactness at a specific scale. The first process is done segmenting LAPAN-A3 images with segmentation criteria that have been determined earlier. Then the tree algorithm is made. The creation of this tree algorithm is fixed so that it can be applied to other regions in addition to the study area with data conditions similar.
The tree algorithm created uses relatively few samples, and separation of the sample is more influenced by user classification. This research uses a tree algorithm because it provides the highest accuracy and precision of the moment this is towards the results of classification as well as requires a short time in the classification process object based. Figure 4 is a tree algorithm created for closing classification land with LAPAN-A3 imagery. Figure 4 is a tree algorithm created for closing classification land with LAPAN-A3 imagery. 


\section{RESULT AND DISCUSSION}

This OBIA classification uses parameters scale 60 , shape 0.5 , and compactness 0.5 . These three parameters are the main parameters in obtaining other parameters. The compactness parameter used is 0.5 . The results of its application are shown in the following figure. The value of 0.5 is applied to the entire LAPAN A3 image.

The results obtained are compactness values 1-9. A value of 1-2 dominates the area in the form of the water class. The land class was dominated in value of 2-4. There are only a few values of 4-9 in the image segmentation results of LAPAN A3. Generally, the value of 4-9 is spread over data in the form of clouds, cloud shadows, no data, and pixel value anomalies. The result of compactness is shown in Fig 5.

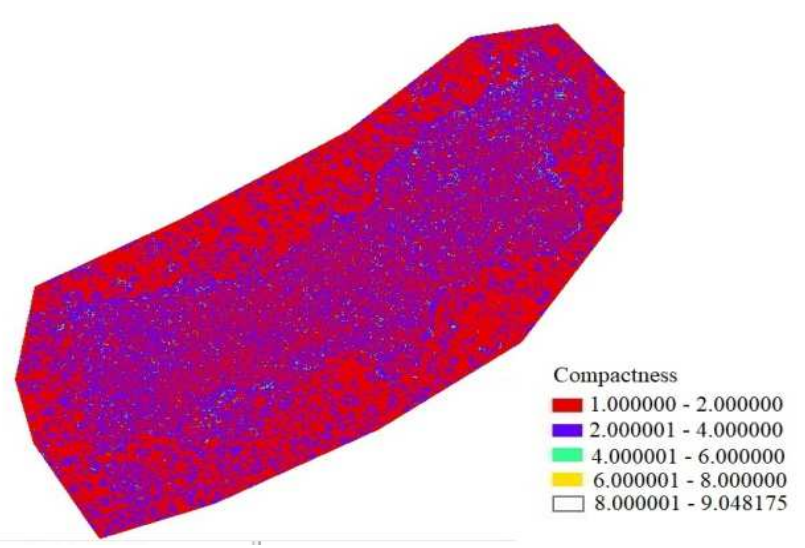

Fig. 5 Result of Compactness parameter

The shape index (2D image) describes the fineness of the image object's boundaries. If the finer the boundaries of an image object, the lower the shape index value. This condition is calculated from the feature of the boundary length of the image object divided by four times the square root of the area. At the time of segmentation, a shape value of 0.5 is used.

This value is applied to the LAPAN A3 image. The results obtained from this application are in the form of shape index values 1-4.8. The water, savanna, steppe, and vegetation classes were dominated in value of 1-2. Value 2-3 dominates the area with open land class, settlement. This shape value determines the size of the object identified. The result of compactness is shown in Fig 6.

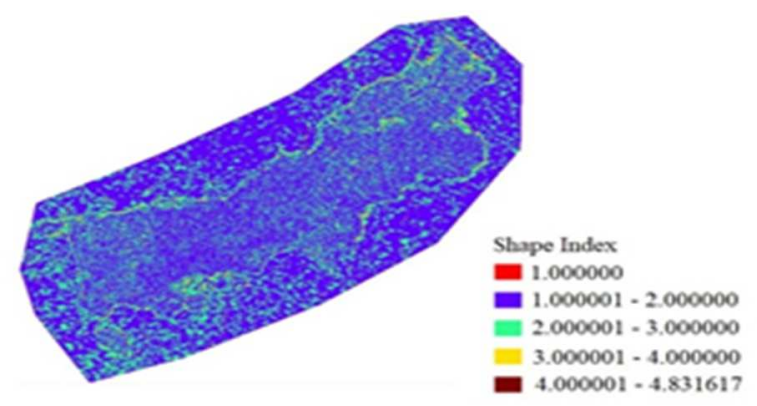

Fig. 6 Result of the shape parameter

The Asymmetry feature describes the relative length of an image object, compared to ordinary polygons. An ellipse is estimated around a given image object, which can be expressed by the ratio of the lengths of the minor to the principal axes. The feature value increases with this asymmetry. 3D asymmetry is calculated from the ratio between the smallest and largest eigenvalues of the image object. Asymmetry is obtained with a value of $0-0.99$. Asymmetry in water and land areas will be more diverse. Result of asymmetry is shown that in Fig 7.

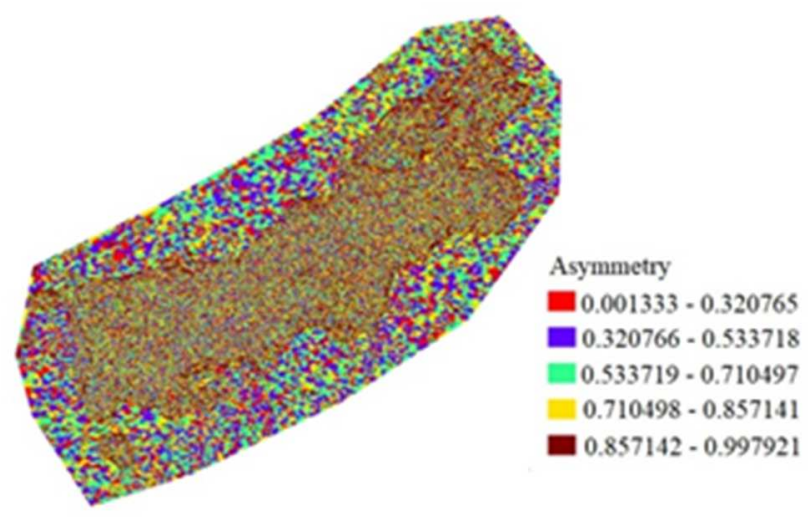

Fig. 7 Result of the Asymmetry parameter

The Density feature describes the distribution in the pixel space of an image object. In OBIA, the most compact form is squared; the more the object is shaped like a filament, the lower the density. Density is calculated by the number of pixels that make up the image object divided by its estimated radius, based on the covariance matrix. The densest shapes for $3 \mathrm{D}$ objects are cubes. The more the object image is in the form of a filament, the lower its density. The value is calculated by dividing the edge of the volume in the cube by the radius of the sphere.

The density value obtained after applying segmentation to the LAPAN A3 image is $0.44-2.28$. The water class is dominated by a density value of $1.49-2.28$. The result of compactness is shown in Fig 8.

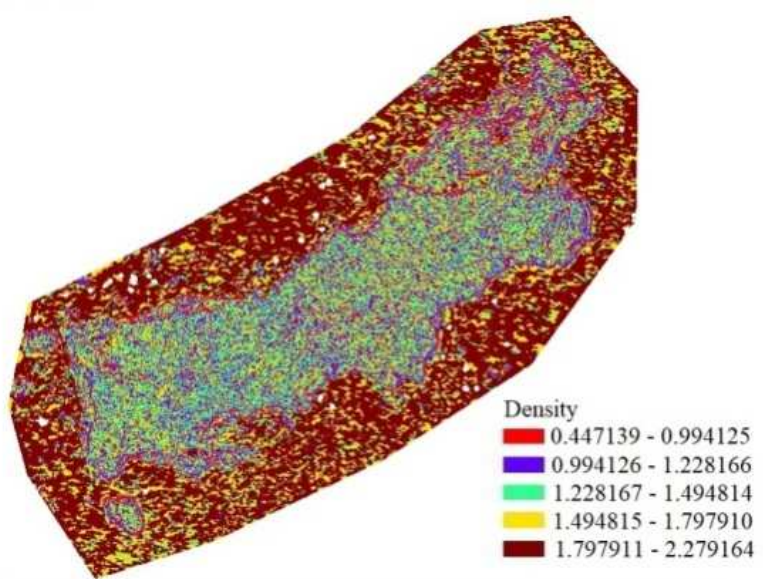

Fig. 8 Result of the density parameter

Three steps were taken to obtain the OBIA classification results, namely segmentation, data analysis, and data export. Segmentation was carried out with a scale of 60 , shape 0.5 , and compactness 0.5 . Then the data analysis was performed using the OBIA method. The results obtained are open land classes, settlements, water bodies, low vegetation, and high vegetation. The result of OBIA classification is shown that in Fig 9. 


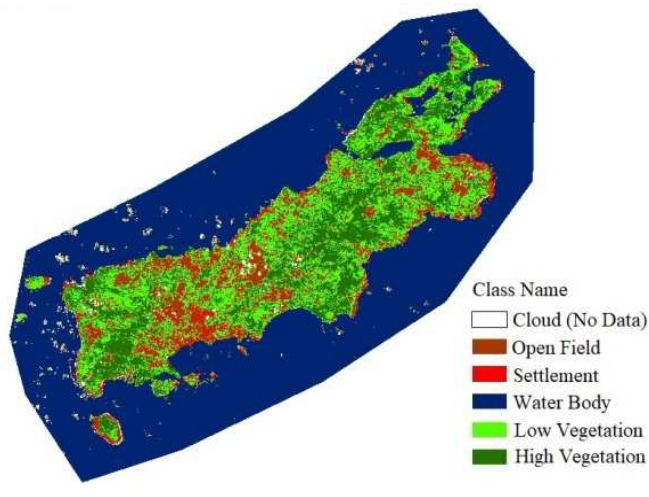

Fig. 9 OBIA Classification result

Based on the results of the OBIA classification on Rote Island, the area of the open land class is $233.67 \mathrm{~km} 2$, the area of the settlement is $11.57 \mathrm{~km} 2$, the body of water is 2006.21 $\mathrm{km} 2$, the area of low vegetation is $525.93 \mathrm{~km} 2$, the area of high vegetation is $437.5 \mathrm{~km} 2$., and there is no data (cloud and cloud shadows) on the LAPAN A3 image of $45.78 \mathrm{~km} 2$. Table 1 shown the Obia classification.

TABLE I

OBIA CLASSIFICATION RESULT

\begin{tabular}{lrrr}
\hline \multicolumn{1}{c}{ Class Name } & Object & \multicolumn{1}{c}{ Area $(\mathbf{m} 2)$} & \multicolumn{1}{c}{ Area $(\mathbf{k m 2})$} \\
\hline Open Field & 40041 & 233671725 & 233,671725 \\
Settlement & 31246 & 110569500 & 110,5695 \\
Body water & 33880 & 2006210250 & 2006,21025 \\
Low vegetation & 64399 & 525927375 & 525,927375 \\
High vegetation & 38290 & 437501250 & 437,50125 \\
No Data & 14568 & 45781425 & 45,781425 \\
\hline
\end{tabular}

The results of the classification in this study were tested for accuracy and precision with a geostatistical approach. This geostatistical test uses three approaches. Classification stability aims to see the stability of an object based on the mean, standard deviation, minimum and maximum values. Checks were carried out on high vegetation classes, low vegetation, open land, settlements, water bodies, and no data. Table 2 presents the conditions of classification stability.

TABLE II

CLASSIFICATION STABILITY

\begin{tabular}{|c|c|c|c|c|c|}
\hline Class & Objects & Mean & StdDev & Min & Max \\
\hline $\begin{array}{l}\text { High } \\
\text { Vegetation }\end{array}$ & 38290 & 0.0055 & 0.0044 & $\begin{array}{l}1.7881 \mathrm{e} \\
-007\end{array}$ & 0.003 \\
\hline $\begin{array}{l}\text { Low } \\
\text { Vegetation }\end{array}$ & 64399 & 0.01034 & 0.00897 & 0 & 0.060 \\
\hline $\begin{array}{l}\text { Open } \\
\text { Field }\end{array}$ & 40041 & 0.01056 & 0.00612 & $\begin{array}{l}4.7683 e \\
-007\end{array}$ & 0.078 \\
\hline Settlement & 31246 & 0.2743 & 0.02538 & $\begin{array}{l}2.9802 \mathrm{e} \\
-007\end{array}$ & 0.148 \\
\hline $\begin{array}{l}\text { Water } \\
\text { body }\end{array}$ & 33880 & 0.0352 & 0.54140 & $\begin{array}{l}2.9802 \mathrm{e} \\
-007\end{array}$ & 0.257 \\
\hline No data & 17288 & 0.1284 & 0.14751 & $\begin{array}{l}2.14576 \\
\mathrm{e}-006\end{array}$ & 1 \\
\hline
\end{tabular}

The next activity was to obtain the best classification results. The geostatistical test approach with this method is similar to classification stability. The difference is in the algorithmic approach by looking for the maximum conditions in each object class. The maximum value is attempted to reach one so that the mean and standard deviation will indirectly increase. However, the correlation value on the same object remains close to one, and the correlation approaches zero on different objects. Table 3 shows the best classification results.

TABLE III

BEST CLASSIFICATION RESULT

\begin{tabular}{llllll}
\hline Class & Objects & Mean & StdDev & Min & Max \\
\hline $\begin{array}{l}\text { High } \\
\text { Vegetatio }\end{array}$ & 38290 & 0.991 & 0.0178 & 0.264 & 1 \\
$\mathrm{n}$ & & & & & \\
$\begin{array}{l}\text { Low } \\
\text { Vegetatio }\end{array}$ & 64399 & 0.983 & 0.0311 & 0.351 & 1 \\
$\mathrm{n}$ & & & & & \\
$\begin{array}{l}\text { Open } \\
\text { Field }\end{array}$ & 40041 & 0.9806 & 0.0220 & 0.743 & 1 \\
$\begin{array}{l}\text { Settelmen } \\
\mathrm{t}\end{array}$ & 31246 & 0.958 & 0.3769 & 0.176 & 1 \\
$\begin{array}{l}\text { Water } \\
\text { body }\end{array}$ & 33880 & 0.985 & 0.0317 & 0.233 & 1 \\
No data & 17288 & 0.831 & 0.1788 & 0,152 & 1 \\
\hline
\end{tabular}

Furthermore, the error matrix is based on samples. This geostatistical test method aims to see the confusion matrix conditions or the error relationship that occurs between object classes by comparing the samples used in the classification and those samples that are considered correct. Table 4 is a matrix display of confusion against samples in object-based classification results on LAPAN A3 in the Rote Ndao region.

TABLE IV

CONFUSION MATRIX

\begin{tabular}{|c|c|c|c|c|c|c|c|}
\hline 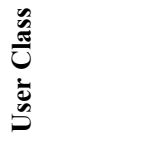 & 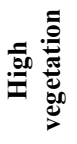 & 㿣。 & 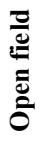 & 苞 & 离 & $\begin{array}{l}\text { İ } \\
\text { D̃ } \\
\text { Z }\end{array}$ & $\Xi$ \\
\hline $\begin{array}{c}\text { High } \\
\text { vegetation }\end{array}$ & 7 & 0 & 0 & 0 & 0 & 0 & 7 \\
\hline $\begin{array}{c}\text { Low } \\
\text { vegetation }\end{array}$ & 0 & 6 & 0 & 0 & 0 & 0 & 6 \\
\hline Open field & 0 & 6 & 9 & 0 & 0 & 0 & 15 \\
\hline Settlement & 0 & 0 & 0 & 6 & 2 & 0 & 8 \\
\hline Water Body & 0 & 0 & 0 & 0 & 13 & 0 & 13 \\
\hline No Data & 0 & 0 & 0 & 0 & 0 & 8 & 8 \\
\hline Unclassified & 0 & 0 & 0 & 0 & 0 & 0 & 0 \\
\hline Sum & 7 & 12 & 9 & 6 & 15 & 8 & \\
\hline
\end{tabular}

The accuracy value obtained is in the form of producer $87.5 \%$, User $80 \%$, Helden $88.89 \%$, Short $80 \%$, and KIA per class $67.16 \%$ and overall, $52.5 \%$. In general, this object-based classification can meet the land cover classification standards international and national levels, namely at $80 \%$.

\section{CONCLUSION}

Object-based classification using the tree method algorithm can increase accuracy greatly geostatistics in the form of producer $86.67 \%$, KIA $83.02 \%$, Helden $92.86 \%$, Short $86.7 \%$, KIA per class $82.72 \%$, and overall, $85.96 \%$. In general, this object-based classification can meet international and national land cover classification standards, namely at $80 \%$. Sample improvement is still needed so that it will be useful to increase the accuracy of the classification results. 


\section{ACKNOWLEDGMENT}

We thank Mr. Mujtahid as director of LAPAN Satellite Technology Center and Mr. Wahyudi Hasbi as chief engineer of LAPAN-IPB satellite for their support and assistance to complete this work well. And also, operator team LAPAN satellite for permits to use this image

\section{REFERENCES}

[1] P. R. Hakim, R. Permala, and A. P. S. Jayani, "Acquisition performance of LAPAN-A3/IPB multispectral imager in real-time mode of operation," in IOP Conference Series: Earth and Environmental Science, 2018, vol. 149, no. 1, doi: 10.1088/17551315/149/1/012061.

[2] P. R. Hakim, A. Hadi Syafrudin, S. Salaswati, S. Utama, and W. Hasbi, "Development of systematic image pre-processing of LAPAN-A3/IPB multispectral images," International Journal Of Advanced Studies In Computer Science In Engineering IJASCSE, Vol 7, pp.9-18, 2018.

[3] A. B. Imran and S. Ahmed, "Potential of Landsat-8 spectral indices to estimate forest biomass," Int. J. Hum. Cap. Urban Manag., vol. 3, no. 4, 2018

[4] L. C. Alatorre et al., "Temporal changes of NDVI for qualitative environmental assessment of mangroves: Shrimp farming impact on the health decline of the arid mangroves in the Gulf of California (1990-2010)," J. Arid Environ., vol. 125, 2016, doi: 10.1016/j.jaridenv.2015.10.010.

[5] K. G. Abrantes, M. Sheaves, and J. Fries, "Estimating the value of tropical coastal wetland habitats to fisheries: Caveats and assumptions," PLoS One, vol. 14, no. 4, 2019, doi: 10.1371/journal.pone.0215350.

[6] D. Phiri, J. Morgenroth, C. Xu, and T. Hermosilla, "Effects of preprocessing methods on Landsat OLI-8 land cover classification using OBIA and random forests classifier," Int. J. Appl. Earth Obs. Geoinf., vol. 73, 2018, doi: 10.1016/j.jag.2018.06.014.

[7] I. L. Sari and S. Fildes, "Land cover classification using Object-Based Image Analysis of SPOT-6 imagery for land cover and forest monitoring in Nagan Raya, Aceh - Indonesia," Int. J. Adv. Sci. Eng. Inf. Technol., vol. 7, no. 6, 2017, doi: 10.18517/ijaseit.7.6.3426.

[8] E. Lichtblau and C. J. Oswald, "Classification of impervious land-use features using object-based image analysis and data fusion," Comput. Environ. Urban Syst., vol. 75, 2019, doi: 10.1016/j.compenvurbsys.2019.01.007.

[9] F. Baker and C. Smith, "A GIS and object based image analysis approach to mapping the greenspace composition of domestic gardens in Leicester, UK," Landsc. Urban Plan., vol. 183, 2019, doi: 10.1016/j.landurbplan.2018.12.002.

[10] R. Comert, U. Avdan, T. Gorum, and H. A. Nefeslioglu, "Mapping of shallow landslides with object-based image analysis from unmanned aerial vehicle data," Eng. Geol., vol. 260, 2019, doi: 10.1016/j.enggeo.2019.105264.
[11] S. Iro, "Land-Cover Removal and Gully Development in Southeas Nigeria: A 30-Year Analysis with Pixel and OBIA Approaches in Juxtaposition," Am. J. Environ. Sci., vol. 16, no. 2, 2020, doi: 10.3844/ajessp.2020.34.47.

[12] A. B. Harto et al., "Identification of banana plants from unmanned aerial vehicles (UAV) photos using object based image analysis (OBIA) method (a case study in Sayang Village, Jatinangor District, West Java)," HAYATI J. Biosci., vol. 26, no. 1, 2019, doi: 10.4308/hjb.26.1.7.

[13] F. Hidayat, A. W. Rudiastuti, and N. Purwono, "GEOBIA an (Geographic) Object-Based Image Analysis for coastal mapping in Indonesia: A Review," in IOP Conference Series: Earth and Environmental Science, 2018, vol. 162, no. 1, doi: 10.1088/17551315/162/1/012039.

[14] D. Stéphane, D. Laurence, G. Raffaele, A. Valérie, and R. Eloise, "Land cover maps of Antananarivo (capital of Madagascar) produced by processing multisource satellite imagery and geospatial reference data," Data Br., vol. 31, 2020, doi: 10.1016/j.dib.2020.105952.

[15] B. A. Robson, T. Bolch, S. MacDonell, D. Hölbling, P. Rastner, and N. Schaffer, "Automated detection of rock glaciers using deep learning and object-based image analysis," Remote Sens. Environ., vol. 250, 2020, doi: 10.1016/j.rse.2020.112033.

[16] A. C. dos S. Luciano et al., "A generalized space-time OBIA classification scheme to map sugarcane areas at regional scale, using Landsat images time-series and the random forest algorithm," Int. J. Appl. Earth Obs. Geoinf., vol. 80, 2019, doi: 10.1016/j.jag.2019.04.013.

[17] P. Amatya, D. Kirschbaum, T. Stanley, and H. Tanyas, "Landslide mapping using object-based image analysis and open source tools," Eng. Geol., vol. 282, 2021, doi: 10.1016/j.enggeo.2021.106000.

[18] C. A. Soares Machado and J. A. Quintanilha, "Identification of trip generators using remote sensing and geographic information system," Transp. Res. Interdiscip. Perspect., vol. 3, 2019, doi: 10.1016/j.trip.2019.100069.

[19] R. M. Simanjuntak, M. Kuffer, and D. Reckien, "Object-based image analysis to map local climate zones: The case of Bandung, Indonesia," Appl. Geogr., vol. 106, 2019, doi: 10.1016/j.apgeog.2019.04.001.

[20] B. Feizizadeh, M. Kazemi Garajeh, T. Blaschke, and T. Lakes, "An object based image analysis applied for volcanic and glacial landforms mapping in Sahand Mountain, Iran," Catena, vol. 198, 2021, doi: 10.1016/j.catena.2020.105073.

[21] A. Dornik, L. Dragut, and P. Urdea, "Classification of Soil Types Using Geographic Object-Based Image Analysis and Random Forests," Pedosphere, vol. 28, no. 6, 2018, doi: 10.1016/S1002-0160(17)603771.

[22] P. R. Hakim, A. H. Syafrudin, and S. Salaswati, "Analysis of radiometric calibration on matrix imager of LAPAN-A3 satellite payload," 2016, doi: 10.1109/ICARES.2015.7429831.

[23] N. M. N. Khamsah, S. Utama, R. H. Surayuda, and P. R. Hakim, "The development of LAPAN-A3 satellite off-nadir imaging mission," 2019, doi: 10.1109/ICARES.2019.8914347. 